\title{
Phase Stability and Site Preference of Tb-Fe-Co-V Compounds
}

\author{
Jing Sun, Jiang Shen, and Ping Qian \\ Institute of Applied Physics, University of Science and Technology, Beijing 100083, China \\ Correspondence should be addressed to Jing Sun; jingsun9713vj@yahoo.com
}

Received 29 April 2013; Accepted 11 June 2013

Academic Editors: S. V. Dmitriev and Z. Zhang

Copyright (C) 2013 Jing Sun et al. This is an open access article distributed under the Creative Commons Attribution License, which permits unrestricted use, distribution, and reproduction in any medium, provided the original work is properly cited.

\begin{abstract}
The effect of cobalt on the structural properties of intermetallic $\mathrm{Tb}_{3} \mathrm{Fe}_{27.4-x} \mathrm{Co}_{x} \mathrm{~V}_{1.6}$ with $\mathrm{Nd}_{3}(\mathrm{Fe}, \mathrm{Ti})_{29}$ structure has been studied by using interatomic pair potentials obtained through the lattice inversion method. Calculated results show that the preferential occupation site of the $\mathrm{V}$ atom is found to be the $4 \mathrm{i}(\mathrm{Fe} 3)$ site, and $\mathrm{Fe}$ atoms are substituted for Co atoms with a strong preference for the $8 \mathrm{j}(\mathrm{Fe} 8)$ site. The calculated lattice constants coincide quite well with experimental values. The calculated crystal structure can recover after either an overall wide-range macrodeformation or atomic random motion, demonstrating that this system has the stable structure of $\mathrm{Nd}_{3}(\mathrm{Fe}, \mathrm{Ti})_{29}$. All these prove the effectiveness of interatomic pair potentials obtained through the lattice inversion method in the description of rare-earth materials.
\end{abstract}

\section{Introduction}

In 1993, it had been first found that the structure of the compound $\mathrm{Nd}_{2} \mathrm{Fe}_{19-x} \mathrm{Ti}_{x}$ suggested to be a $\mathrm{Nd}_{3}(\mathrm{Fe}, \mathrm{Ti})_{29^{-}}$ type structure with monoclinic symmetry [1]. After lots of investigation and disputation [2-4], it indicates that the Space Group (S.G.) of $\mathrm{Nd}_{3}(\mathrm{Fe}, \mathrm{Ti})_{29}$-type structure belongs to $\mathrm{A} 2 / \mathrm{m}$ rather than $\mathrm{P} 2{ }_{1} / \mathrm{c}$.

In the $\mathrm{A} 2 / \mathrm{m}$ space group description, the lattice cell with two $\mathrm{R}_{3} \mathrm{Fe}_{29}$ formulas consists of 64 atoms. The rare-earth ions occupy two nonequivalent crystallographic sites (2a and 4i), and the iron atoms occupy 11 sites (one $2 \mathrm{c}$, one $4 \mathrm{~g}$, one $4 \mathrm{e}$, four $4 \mathrm{i}$ and four $8 \mathrm{j}$ ). The crystallographic data for $\mathrm{Nd}_{3} \mathrm{Fe}_{27.5} \mathrm{Ti}_{1.5}$ compound (Space Group no. 12 (A2/m), A12/m1, unique axis b, cell choice 2) is on page 161 of [5]. The $3: 29$ compounds are deemed to consist of tetragonal $\mathrm{ThMn}_{12}$-type $(1: 12)$ and rhombohedral $\mathrm{Th}_{2} \mathrm{Ni}_{17}$-type $(2: 17)$ segments in a ratio of $1: 1$ [6]. In fact, the binary compounds $\mathrm{R}_{3} \mathrm{Fe}_{29}$ are metastable, which can be seen as the intrinsic prototype of $\mathrm{R}_{3}(\mathrm{Fe}, \mathrm{T})_{29}$, since $\mathrm{R}_{3}(\mathrm{Fe}, \mathrm{T})_{29}$ can be made stable with a moderate amount of a ternary element $\mathrm{T}(\mathrm{T}=\mathrm{V}, \mathrm{Ti}, \mathrm{Cr}$, or Mo, etc.). From that time on, the ternary intermetallic compounds $\mathrm{R}_{3}(\mathrm{Fe}, \mathrm{T})_{29}(\mathrm{R}=$ a rare-earth element or $\mathrm{Y}$, and $\mathrm{T}=\mathrm{a}$ stabilizing element) have attracted attention, as well as many quaternary compounds [7-14].
As well known, the substitution of cobalt for iron in rare-earth-transition metal intermetallics has a remarkable effect on their magnetic properties. Comparing with iron, cobalt has a different electronic structure and therefore lead to a different local anisotropy. Hence, the structure and the magnetic properties of $3: 29$ compounds are strongly affected by the substitution of iron by cobalt. However, when more than $40 \%$ of substitution of iron by cobalt atoms occurs, a large number of stabilizing atoms are demanded. If not, a disordered modification of hexagonal $\mathrm{Th}_{2} \mathrm{Ni}_{17}$-type structure will be formed [10, 11, 13, 14].

So far, there are some investigations on the $\mathrm{Tb}-\mathrm{Fe}-\mathrm{Co}-\mathrm{V}$ and Tb-Fe-Co-Cr systems [9, 11-14]. For $\mathrm{Tb}_{3} \mathrm{Fe}_{29-x} \mathrm{~V}_{x}$ compounds, in the temperature range between $5 \mathrm{~K}$ and $200 \mathrm{~K}$, a FOMP occurs [15]. The spin reorientation has been observed in the $\mathrm{Tb}-\mathrm{Fe}-\mathrm{Co}-\mathrm{V}$ system, and the Curie temperature and saturation magnetisation decrease with the increase of Co content [13].

In this paper, our investigation focuses on the phase stability and site preference of Co in $\mathrm{Tb}_{3} \mathrm{Fe}_{27.4-x} \mathrm{Co}_{x} \mathrm{~V}_{1.6}(x$ $=0.0,0.1,0.2,0.3$ and 0.4 ) compounds. The interatomic pair potential are obtained by Chen's lattice inversion method, whose theory is exhibited in the second part. The comparison of the calculated results with the experimental data is shown 
in Section 3. And the fourth part is the conclusion and discussion.

\section{Methodology}

Chen et al. proposed a concise inverse method [16-21] based on the modified Möbius inversion in number theory, which can be applied to obtain the photon density of states [16], to solve the inverse blackbody radiation problem for remote sensing [16], to unify the Debye and Einstein approximations in a general mathematics system [20], and to extract the interatomic pair potentials from ab initio calculated cohesive energy curves in pure metals and intermetallic compounds [17-19, 22, 23], metal/ceramic interface [24], and metal/oxide interface [25], as well as in carbides with complex structures [26-28], with high convergence speed.

Here, we take a single element crystal as an example to explain how to use Chen's lattice inversion theorem to obtain the interatomic pair potential from the first-principle cohesive energy curve. Suppose that the crystal cohesive energy can be expressed as the sum of interatomic pair potentials

$$
E(x)=\frac{1}{2} \sum_{r_{i} \neq 0} \varphi\left(\vec{r}_{i}\right)=\frac{1}{2} \sum_{n=1}^{\infty} r_{0}(n) \varphi\left[b_{0}(n) x\right],
$$

where $x$ is the nearest neighbor distance, $\vec{r}_{i}$ is the position vector of the $i$ th atom in the lattice, $b_{0}(n) x$ is the $n$th nearest neighbour distance with $b_{0}(1)=1$, and $r_{0}(n)$ is the $n$th coordination number. Obviously, $\left\{b_{0}\right\}$ is a totally ordered set but, in most cases, not a multiplicative semigroup. In this case, we need to extend it to a totally ordered multiplicative semigroup $\{b\}$ with $b(1)=b_{0}(1)=1$. Namely, for any $b(j)$, $b(k) \in\{b\}$, we have $b(j) b(k) \in\{b\}$. Now $E(x)$ can be rewritten as

$$
E(x)=\frac{1}{2} \sum_{n=1}^{\infty} r(n) \varphi[b(n) x]
$$

where the extended coordination number $r(n)$ satisfies the following rule:

$$
r(n)= \begin{cases}r_{0}\left(b_{0}^{-1}[b(n)]\right), & b(n) \in\left\{b_{0}\right\}, \\ 0, & b(n) \notin\left\{b_{0}\right\} .\end{cases}
$$

It is clear that $\{r(n)\}$ is uniquely determined by crystal geometrical structure. Now we can extract pair potential $\varphi$ from (2) as

$$
\varphi(x)=2 \sum_{n=1}^{\infty} I(n) E[b(n) x]
$$

where $I(n), n=1,2, \ldots, \infty$, and any $b(n)$ satisfying $b(n) \mid$ $b(t),\{I(n)\}$ can be determined by

$$
\begin{array}{r}
\sum_{b(n) \mid b(t)} I\left(b^{-1}[b(n)]\right) r\left(b^{-1}\left[\frac{b(t)}{b(n)}\right]\right)=\delta_{t, 1} \\
(t=1,2, \ldots, \infty),
\end{array}
$$

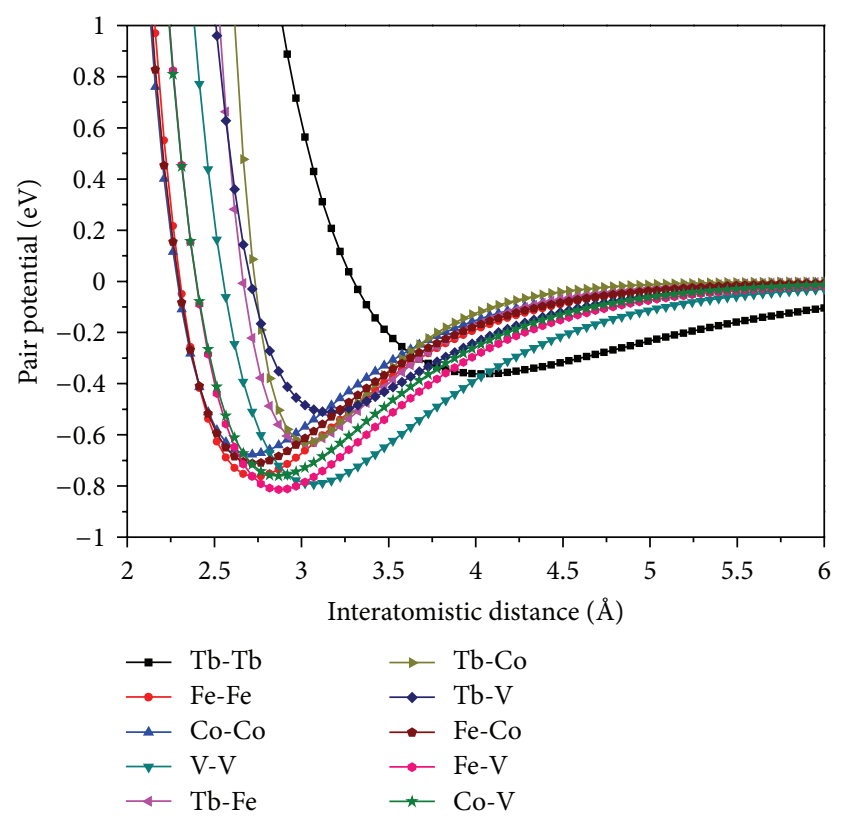

Figure 1: Potentials in the system of Tb-Fe-Co-V.

where $\delta$ is the Kronecker delta. It is easy to prove that (5) has and only has a single solution set $\{I(n)\}$, which, like $r\{(n)\}$, is uniquely determined by crystal geometrical structure, not related to element category.

This means that we can take advantage of number theory to extract the interatomic pair potentials form cohesive energy curve(s). At this stage, modified Möbius inversion can be adopted to extract the pair potential curve data and then fit these data on the basis of Morse function [29] to determine the potential parameters. Consider

$$
\varphi(x)=D_{0}\left(e^{-\gamma\left(x / R_{0}-1\right)}-2 e^{-(\gamma / 2)\left(x / R_{0}-1\right)}\right),
$$

where $x$ indicates the distance between two atoms and $R_{0}$ is the equilibrium distance, with $D_{0}$ and $\gamma$ being parameters without unit.

For the readers' convenience, several important potential parameters are shown in Figure 1.

\section{Calculated Results}

In this paper, energy minimization is carried out using a conjugate gradient method. The cut-off radius is $14 \AA$. In order to reduce statistical fluctuation, we take the super-cell containing 1280 atoms, $\left(\mathrm{Tb}_{3} \mathrm{Fe}_{27.4-x} \mathrm{Co}_{x} \mathrm{~V}_{1.6}\right)_{40}$, for simulation.

There are no reports in the literature on the existence of the binary structure $\mathrm{Tb}_{3} \mathrm{Fe}_{29}$, which can be seen as the prototype of $\mathrm{R}_{3}(\mathrm{Fe}, \mathrm{T})_{29}$. In the calculation procedure, the initial lattice constants of $\mathrm{Tb}_{3} \mathrm{Fe}_{29}$ are randomly chosen in a certain range. Under the control of the interatomic pair potentials, the energy minimization is carried out. After repeated relaxation, the space group maintains $A 2 / m$, the atomic site occupation is similar to that of $\mathrm{Nd}_{3}(\mathrm{Fe}, \mathrm{Ti})_{29}$, and the structure will be stabilized with lattice constants 


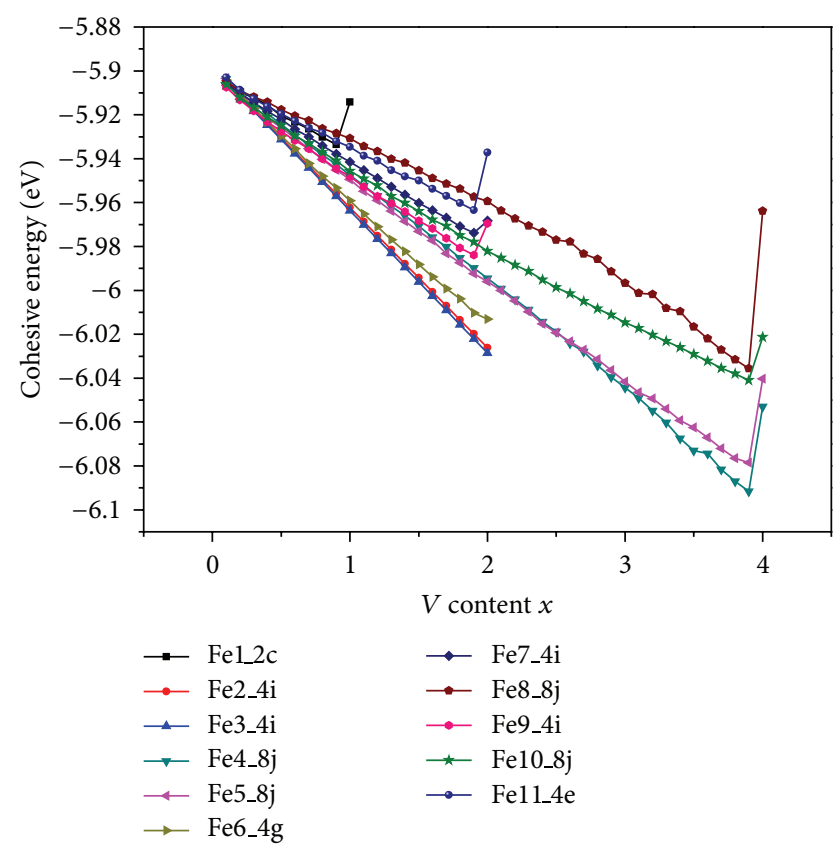

Figure 2: Calculated cohesive energy of $\mathrm{Tb}_{3} \mathrm{Fe}_{29-x} \mathrm{~V}_{x}$ as a function of the $\mathrm{V}$ content $x$.

TABLE 1: Final crystal lattice constants of $\mathrm{Tb}_{3} \mathrm{Fe}_{29}$ corresponding to random initial structures.

\begin{tabular}{lccc}
\hline \multicolumn{2}{c}{ Initial state } & \multicolumn{2}{c}{ Final state } \\
$a, b, c(\AA)$ & $\alpha, \beta, \gamma(\mathrm{deg})$ & $a, b, c(\AA)$ & $\alpha, \beta, \gamma(\mathrm{deg})$ \\
\hline $10,8,9$ & $90,95,90$ & $10.525,8.433,9.696$ & $90,96.91,90$ \\
$11,10,10$ & $90,100,90$ & $10.525,8.433,9.696$ & $90,96.91,90$ \\
$10,10,10$ & $90,90,90$ & $10.525,8.433,9.696$ & $90,96.91,90$ \\
$13,10,10$ & $90,95,90$ & $10.525,8.433,9.696$ & $90,96.91,90$ \\
$12,12,12$ & $90,90,90$ & $10.525,8.433,9.696$ & $90,96.91,90$ \\
$10,10,10$ & $85,90,88$ & $10.525,8.433,9.696$ & $90,96.91,90$ \\
$8,8,8$ & $90,90,90$ & $10.525,8.433,9.696$ & $90,96.91,90$ \\
\hline
\end{tabular}

$a=10.525 \AA, b=8.433 \AA, c=9.696 \AA$, and $\beta=96.91^{\circ}$ (Table 1). The randomness of the initial structure in a certain range and the stability of the final structure illustrate that $\mathrm{Tb}_{3} \mathrm{Fe}_{29}$ has the topological invariability with respect to the existing $\mathrm{Nd}_{3}(\mathrm{Fe}, \mathrm{Ti})_{29}$ structure. Hence, it furnishes convincing evidence that the interatomic pair potentials are reliable for the study of structural material characteristics.

Substitute the atoms of ternary element vanadium for the randomly chosen iron atoms at a certain lattice site, and then make the lattice relaxation. In this calculation procedure, energy minimization is taken as a criterion of the stability. The cohesive energy of $\mathrm{Tb}_{3} \mathrm{Fe}_{29-x} \mathrm{~V}_{x}$ on the content of ternary addition is evaluated and illustrated in Figure 2. The values of energy in the figure are statistically averaged over the calculations of 20 samples. Figure 2 shows that the cohesive energy is lower when $\mathrm{V}$ atoms are substituted for Fe atoms at the $4 \mathrm{i}(\mathrm{Fe} 3)$ site than the other sites, so $\mathrm{V}$ should prefer the $4 \mathrm{i}(\mathrm{Fe} 3)$ site for $x \leq 2.0$. The calculated lattice constants of compound $\mathrm{Tb}_{3} \mathrm{Fe}_{27.4} \mathrm{~V}_{1.6}$ are compared with the experimental

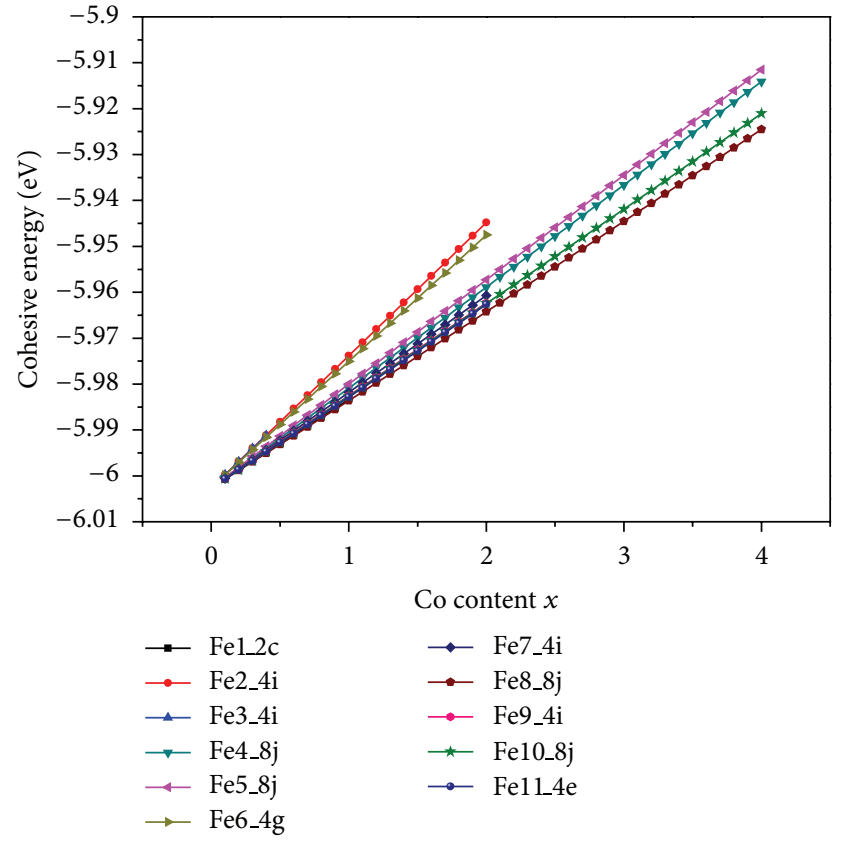

Figure 3: Calculated cohesive energy of $\mathrm{Tb}_{3} \mathrm{Fe}_{27.4-x} \mathrm{Co}_{x} \mathrm{~V}_{1.6}$ as a function of the Co content $x$.

values [13], which are shown in Table 2. Substitute the $\mathrm{V}$ atoms for a randomly selected part of $\mathrm{Fe}$ atoms at the $4 \mathrm{i}(\mathrm{Fe} 3)$ sites, thus forming the $\left(\mathrm{Tb}_{3} \mathrm{Fe}_{27.4} \mathrm{~V}_{1.6}\right)_{40}$. Then make use of the conjugate gradient method to minimize the system energy, as an approximation of a practical relaxation process. Furthermore, we take the $\left(\mathrm{Tb}_{3} \mathrm{Fe}_{27.4} \mathrm{~V}_{1.6}\right)_{40}$ structure with each atom random shifted $0.6 \AA$ from their equilibrium position to test the structural stability. Each atom in a disturbed cell can recover its equilibrium position under the interaction of interatomic pair potentials. The results show that the lattice constants are in good agreement with the experimental data [13], still retaining $a=10.5433 \AA, b=8.4647 \AA, c=9.7196 \AA$, and $\beta=97.0681^{\circ}$ (Table 3 ). Thus, the stability of the lattice and the effectiveness of the interatomic pair potentials are verified.

In $\mathrm{Tb}_{3} \mathrm{Fe}_{27.4-x} \mathrm{Co}_{x} \mathrm{~V}_{1.6}$ compounds, substitute the atoms of quaternary element cobalt for the randomly chosen iron atoms at a certain lattice site, and then make the lattice relaxation. Based on the ternary compounds $\mathrm{Tb}_{3} \mathrm{Fe}_{27.4} \mathrm{~V}_{1.6}$ and the site occupation of cobalt in quaternary system $\mathrm{Tb}_{3} \mathrm{Fe}_{27.4-x} \mathrm{Co}_{x} \mathrm{~V}_{1.6}$ has been investigated. The dependences of the cohesive energy of $\mathrm{Tb}_{3} \mathrm{Fe}_{27.4-x} \mathrm{Co}_{x} \mathrm{~V}_{1.6}$ on the content of quaternary addition are evaluated and illustrated in Figure 3. It is shown that the calculated cohesive energy increases least significantly while cobalt atoms occupy $8 \mathrm{j}(\mathrm{Fe} 8)$ site. Therefore, Fe atoms are substituted for Co atoms with a strong preference for the $8 \mathrm{j}(\mathrm{Fe} 8)$ site. The calculated lattice constants are compared with the experimental values [13], which are shown in Table 2. It states clearly that the lattice parameters $a, b$ (but not $c$ ) of the compounds are decreased with increasing cobalt concentration due to the fact that the iron atoms are replaced by the smaller cobalt atoms. 
TABLE 2: Comparison of calculated and experimental unit cell parameters.

\begin{tabular}{|c|c|c|c|c|c|}
\hline & $\begin{array}{c}x=0 \\
\mathrm{~Tb}_{3} \mathrm{Fe}_{27.4} \mathrm{~V}_{1.6}\end{array}$ & $\begin{array}{c}x=0.1 \\
\mathrm{~Tb}_{3} \mathrm{Fe}_{27.3} \mathrm{Co}_{0.1} \mathrm{~V}_{1.6}\end{array}$ & $\begin{array}{c}x=0.2 \\
\mathrm{~Tb}_{3} \mathrm{Fe}_{27.2} \mathrm{Co}_{0.2} \mathrm{~V}_{1.6}\end{array}$ & $\begin{array}{c}x=0.3 \\
\mathrm{~Tb}_{3} \mathrm{Fe}_{27.1} \mathrm{Co}_{0.3} \mathrm{~V}_{1.6}\end{array}$ & $\begin{array}{c}x=0.4 \\
\mathrm{~Tb}_{3} \mathrm{Fe}_{27.0} \mathrm{Co}_{0.4} \mathrm{~V}_{1.6}\end{array}$ \\
\hline \multicolumn{6}{|l|}{$a(\AA)$} \\
\hline Cal. & 10.5433 & 10.5424 & 10.5418 & 10.5411 & 10.5406 \\
\hline Exp. & 10.557 (1) & 10.545 (1) & $10.537(1)$ & $10.519(1)$ & $10.511(1)$ \\
\hline Err. (\%) & -0.1298 & -0.0247 & 0.2168 & 0.2101 & 0.2816 \\
\hline \multicolumn{6}{|l|}{$b(\AA)$} \\
\hline Cal. & 8.4647 & 8.4647 & 8.4643 & 8.4638 & 8.4635 \\
\hline Exp. & 8.497 (1) & $8.496(1)$ & $8.490(1)$ & $8.476(1)$ & $8.461(1)$ \\
\hline Err. (\%) & -0.3801 & -0.3684 & -0.3027 & -0.1439 & 0.0295 \\
\hline \multicolumn{6}{|l|}{$c(\AA)$} \\
\hline Cal. & 9.7196 & 9.7189 & 9.7185 & 9.7181 & 9.7176 \\
\hline Exp. & 9.669 (1) & $9.672(1)$ & 9.669 (1) & 9.658 (1) & $9.645(1)$ \\
\hline Err. (\%) & 0.5233 & 0.4849 & 0.5119 & 0.6223 & 0.7527 \\
\hline \multicolumn{6}{|l|}{$\beta(\operatorname{deg})$} \\
\hline Cal. & 97.0681 & 97.0703 & 97.0698 & 97.0690 & 97.0691 \\
\hline Exp. & 96.89 & 96.72 & 96.72 & 96.71 & 96.74 \\
\hline Err. (\%) & 0.18 & 0.31 & 0.3617 & 0.3712 & 0.3402 \\
\hline
\end{tabular}

TABLE 3: Comparison of related lattice constants before and after atomic random motion of $0.6 \AA$ for $\mathrm{Tb}_{3} \mathrm{Fe}_{27.4} \mathrm{~V}_{1.6}$.

\begin{tabular}{lcccc}
\hline & $a(\AA)$ & $b(\AA)$ & $c(\AA)$ & $\beta(\mathrm{deg})$ \\
\hline Before random motion & 10.5433 & 8.4647 & 9.7196 & 97.0681 \\
After random motion of & 10.5433 & 8.4647 & 9.7196 & 97.0681 \\
$0.6 \AA$ & $10.557(1)$ & $8.497(1)$ & $9.669(1)$ & 96.89 \\
\hline Experimental [13] & &
\end{tabular}

TABLE 4: The cell constants of $\mathrm{Tb}_{3} \mathrm{Fe}_{27.4-x} \mathrm{Co}_{x} \mathrm{~V}_{1.6}$ under different temperatures.

\begin{tabular}{lccccc}
\hline Compounds & Temperature & $a(\AA)$ & $b(\AA)$ & $c(\AA)$ & $\beta(\mathrm{deg})$ \\
\hline \multirow{4}{*}{$x=0.0$} & $300 \mathrm{~K}$ & 10.5269 & 8.4339 & 9.6954 & 96.8980 \\
& $500 \mathrm{~K}$ & 10.5229 & 8.4309 & 9.6962 & 96.9095 \\
& $700 \mathrm{~K}$ & 10.5250 & 8.4360 & 9.6958 & 96.9115 \\
\hline \multirow{3}{*}{$x=0.1$} & $300 \mathrm{~K}$ & 10.5240 & 8.4329 & 9.6952 & 96.9190 \\
& $500 \mathrm{~K}$ & 10.5241 & 8.4317 & 9.6952 & 96.8885 \\
& $700 \mathrm{~K}$ & 10.5252 & 8.4320 & 9.6950 & 96.9185 \\
\hline \multirow{4}{*}{$x=0.2$} & $300 \mathrm{~K}$ & 10.5249 & 8.4310 & 9.6954 & 96.9180 \\
& $500 \mathrm{~K}$ & 10.5241 & 8.4309 & 9.6954 & 96.9025 \\
& $700 \mathrm{~K}$ & 10.5220 & 8.4330 & 9.6962 & 96.9195 \\
\hline \multirow{4}{*}{$x=0.3$} & $300 \mathrm{~K}$ & 10.5250 & 8.4331 & 9.6959 & 96.9195 \\
& $500 \mathrm{~K}$ & 10.5280 & 8.4328 & 9.6962 & 96.9005 \\
& $700 \mathrm{~K}$ & 10.5282 & 8.4331 & 9.6950 & 96.9095 \\
\hline \multirow{4}{*}{$x=0.4$} & $300 \mathrm{~K}$ & 10.5252 & 8.4338 & 9.6962 & 96.9000 \\
& $500 \mathrm{~K}$ & 10.5252 & 8.4313 & 9.6960 & 96.8990 \\
& $700 \mathrm{~K}$ & 10.5229 & 8.4330 & 9.6956 & 96.9180 \\
\hline
\end{tabular}

The stability of the calculated structure is further checked through molecular dynamics. The cell constants are traced to higher temperatures, as shown in Table 4. Using MD (molecular dynamics) NPT ensemble, with $P=1 \mathrm{~atm}, t$ $=0.001 \mathrm{ps}$, dynamic simulations for $\mathrm{Tb}_{3} \mathrm{Fe}_{27.4-x} \mathrm{Co}_{x} \mathrm{~V}_{1.6}$ are carried out at temperatures of 300,500 , and $700 \mathrm{~K}$. The lattice constants change very little with respect to temperature variation, thus the structural stability is again verified. The comparisons of potential energy and kinetic energy at different temperatures are shown in Table 5 . It can be seen from the table that both the values of potential energy and kinetic energy increase with the increasing temperature, but the contribution of interatomic potentials to the internal energy of the system is much larger than that from thermal motion energy. Therefore, the crystal structure at different temperature is basically determined by the interatomic pair potentials.

\section{Conclusions}

In this paper, we have made an investigation of the phase stability and effect of cobalt atoms element on the structural properties of $\mathrm{Tb}_{3} \mathrm{Fe}_{27.4-x} \mathrm{Co}_{x} \mathrm{~V}_{1.6}$ crystals. The energies of the $\mathrm{Tb}-\mathrm{Fe}-\mathrm{Co}-\mathrm{V}$ systems are calculated from these effective interatomic pair potentials. The calculation results show that vanadium atoms preferentially occupy $4 \mathrm{i}(\mathrm{Fe} 3)$ site, and cobalt prefer the $8 \mathrm{j}(\mathrm{Fe} 8)$ site. Besides, due to the fact that iron atoms are replaced by the smaller cobalt atoms, the lattice parameters $a, b$ (but not $c$ ) of the compounds decreased with increased concentration.

Above all, with the interatomic potentials from lattice inversion, the structural properties have been well reproduced and are in agreement with the experimental data. This suggests that the potentials are successfully used to calculate the structural properties of rare-earth compounds 
TABLE 5: The potential and kinetic energies of $\mathrm{Tb}_{3} \mathrm{Fe}_{27.4-x} \mathrm{Co}_{x} \mathrm{~V}_{1.6}$ under different temperatures.

\begin{tabular}{|c|c|c|c|c|c|}
\hline Compounds & Temperature & $E_{p}(\mathrm{eV})$ & $E_{k}(\mathrm{eV})$ & $E_{\text {total }}(\mathrm{eV})$ & $\overline{E_{p} / E_{\text {total }}}$ \\
\hline \multirow{3}{*}{$x=0.0$} & $300 \mathrm{~K}$ & -1907.8644 & 12.4699 & -1895.3944 & 1.0066 \\
\hline & $500 \mathrm{~K}$ & -1898.9049 & 20.1887 & -1878.7162 & 1.0107 \\
\hline & $700 \mathrm{~K}$ & -1891.3703 & 29.0479 & -1862.3224 & 1.0156 \\
\hline \multirow{3}{*}{$x=0.1$} & $300 \mathrm{~K}$ & -1907.4917 & 12.7817 & -1894.7100 & 1.0067 \\
\hline & $500 \mathrm{~K}$ & -1898.5085 & 20.1824 & -1878.3261 & 1.0107 \\
\hline & $700 \mathrm{~K}$ & -1889.7135 & 27.8954 & -1861.8181 & 1.0150 \\
\hline \multirow{3}{*}{$x=0.2$} & $300 \mathrm{~K}$ & -1907.2399 & 13.0351 & -1894.2048 & 1.0069 \\
\hline & $500 \mathrm{~K}$ & -1898.6019 & 20.8418 & -1877.7601 & 1.0111 \\
\hline & $700 \mathrm{~K}$ & -1890.0060 & 28.8429 & -1861.1631 & 1.0155 \\
\hline \multirow{3}{*}{$x=0.3$} & $300 \mathrm{~K}$ & -1905.9974 & 12.4685 & -1893.5289 & 1.0066 \\
\hline & $500 \mathrm{~K}$ & -1897.0235 & 19.9308 & -1877.0927 & 1.0106 \\
\hline & $700 \mathrm{~K}$ & -1889.9966 & 29.3169 & -1860.6797 & 1.0158 \\
\hline \multirow{3}{*}{$x=0.4$} & $300 \mathrm{~K}$ & -1905.6689 & 12.7901 & -1892.8788 & 1.0068 \\
\hline & $500 \mathrm{~K}$ & -1898.0230 & 21.6214 & -1876.4016 & 1.0115 \\
\hline & $700 \mathrm{~K}$ & -1889.3255 & 29.3861 & -1859.9394 & 1.0158 \\
\hline
\end{tabular}

$\mathrm{Tb}_{3} \mathrm{Fe}_{27.4-x} \mathrm{Co}_{x} \mathrm{~V}_{1.6}$, which is important for future work on material structure research.

\section{Acknowledgments}

This work was supported by the 973 Project in China (no. 2011CB606401) and the National Natural Science Foundation of China (Grant no. 50971024).

\section{References}

[1] S. J. Collotcott, R. K. Day, J. B. Dunlop, and R. L. Davis, "Preparation and Properties of Iron-Rich Nd-Fe-Ti Intermetallic Compounds and Their Nitrides," in Proceedings of the 7th International Symposium on Magnetic Anisotropy and Coercivity in R-T alloys, p. 437, Canberra, Australia, 1992.

[2] H. Pan, Y. Chen, X. Han, C. Chen, and F. Yang, "Structural characterization of the ternary phase $\mathrm{R}_{3}(\mathrm{Fe}, \mathrm{Mo})_{29}$ ( $\mathrm{R}=$ rare earth)," Journal of Magnetism and Magnetic Materials, vol. 185, no. 1, pp. 77-84, 1998.

[3] V. Psycharis, O. Kalogirou, E. Devlin, M. Gjoka, A. Simopoulos, and D. Niarchos, "Structural and intrinsic magnetic material parameters of $\operatorname{Pr}_{3}(\mathrm{Fe}, \mathrm{Ti})_{29}$ and $\operatorname{Pr}_{3}(\mathrm{Fe}, \mathrm{Ti})_{29} \mathrm{~N}_{x}$, Journal of Magnetism and Magnetic Materials, vol. 153, p. 75, 1996.

[4] S.-Q. Hao, N.-X. Chen, and J. Shen, "The Space Group of $\mathrm{Nd}_{3} \mathrm{Fe}_{29-x} \mathrm{Ti}_{x}: \mathrm{A} 2 / \mathrm{m}$ or $\mathrm{P}_{1} /$ c," Physica Status Solidi B, vol. 234, no. 2, pp. 487-495, 2002.

[5] International Tables for Crystallography, Vol. A, Space-Group Symmetry, D. Reidel, Dordrecht, The Netherlands, 1983.

[6] X. F. Han, H. G. Pan, H. Liu, F. Yang, and Y. Zheng, "Syntheses and magnetic properties of $\mathrm{Tb}_{3} \mathrm{Fe}_{29-x} \mathrm{Cr}_{x}$ compounds," Physical Review B, vol. 56, no. 14, pp. 8867-8875, 1997.

[7] H. Z. Luo, Y. X. Li, L. Jia et al., "Structure and magnetic properties of $\mathrm{Er}_{3} \mathrm{Fe}_{29-x} \mathrm{Cr}_{x}$ compounds," Journal of Alloys and Compounds, vol. 397, no. 1-2, pp. 31-36, 2005.

[8] L. Jia, H. Z. Luo, J. Shen et al., "Structure and magnetic properties of $\mathrm{Er}_{3} \mathrm{Fe}_{29-x} \mathrm{Nb}_{x}$," Journal of Physics D, vol. 38, no. 5, p. 667, 2005.
[9] A. Gholizadeh, N. Tajabor, M. Behdani et al., "Anisotropy and FOMP in $\mathrm{Tb}_{3}\left(\mathrm{Fe}_{28-x} \mathrm{Co}_{x}\right)$ V1.0 $(x=0,3$ and 6) compounds," Physica B, vol. 406, no. 18, pp. 3465-3469, 2011.

[10] N. Sheloudko, C. Sarafidis, M. Gjoka, K. G. Efthimiadis, and O. Kalogirou, "Magnetic anisotropy of Ho-Fe-Co-Cr intermetallic compounds," Journal of Alloys and Compounds, vol. 482, no. 1-2, pp. 19-22, 2009.

[11] K. G. Efthimiadis, C. Sarafidis, M. Gjoka, and O. Kalogirou, "Existence and properties of Co-rich 3:29-type of compounds synthesized with heavy rare earths," Journal of Magnetism and Magnetic Materials, vol. 316, no. 2, pp. e458-e461, 2007.

[12] O. Kalogirou, C. Sarafidis, K. G. Efthimiadis, and M. Gjoka, "Influences of Co on structural and magnetic properties of $\mathrm{R}_{3}\left(\mathrm{Fe}_{1-x} \mathrm{Co}_{x}\right)_{29-y} \mathrm{M}_{y}(\mathrm{R}=$ rare earth metal, $\mathrm{M}=$ transition metal) intermetallic compounds," Journal of Alloys and Compounds, vol. 423, no. 1-2, pp. 4-9, 2006.

[13] O. Kalogirou, C. Sarafidis, M. Gjoka, and G. Litsardakis, "Effects of Co substitution on structural and magnetic properties of R3(Fe1-xCox)29-y Vy (R = Tb, Dy)," Journal of Magnetism and Magnetic Materials, vol. 247, no. 1, pp. 34-41, 2002.

[14] D. Hadjiapostolidou, M. Gjoka, C. Sarafidis, E. Pavlidou, T. Bakas, and O. Kalogirou, "Structural and magnetic properties of rare earth-iron-cobalt-vanadium intermetallic compounds ( $\mathrm{R}$ : Tb, Dy)," Journal of Alloys and Compounds, vol. 367, no. 1-2, pp. 255-261, 2004.

[15] D. Courtois, H. S. Li, J. M. Cadogan, D. Givord, and E. BourgeatLami, "Magnetization curves of a $\mathrm{Tb}_{3}(\mathrm{Fe}, \mathrm{V})_{29}$ single crystal," IEEE Transactions on Magnetics, vol. 33, no. 5, pp. 3844-3846, 1997.

[16] N. X. Chen, "Modified Möbius inverse formula and its applications in physics," Physical Review Letters, vol. 64, no. 11, pp. 1193-1195, 1990.

[17] N. X. Chen and G. B. Ren, "Carlsson-Gelatt-Ehrenreich technique and the Möbius inversion theorem," Physical Review B, vol. 45, no. 14, pp. 8177-8180, 1992.

[18] N. X. Chen, Z. D. Chen, Y. N. Shen, S. Liu, and M. Li, “3D inverse lattice problems and Möbius inversion," Physics Letters A, vol. 184, no. 4-5, pp. 347-351, 1994.

[19] N. X. Chen, Z. D. Chen, and Y. C. Wei, "Multidimensional inverse lattice problem and a uniformly sampled arithmetic 
Fourier transform," Physical Review E, vol. 55, no. 1, pp. R5-R8, 1997.

[20] N. X. Chen and E. Q. Rong, "Unified solution of the inverse capacity problem," Physical Review E, vol. 57, no. 2, pp. 13021308, 1998.

[21] Y. Liu, N. X. Chen, and Y. M. Kang, "Virtual lattice technique and the interatomic potentials of zinc-blend-type binary compounds," Modern Physics Letters B, vol. 16, pp. 187-194, 2002.

[22] H. Y. Wang, F. A. Zhao, and N. X. Chen, "Theoretical investigation on the phase stability of $\mathrm{Nd}_{2} \mathrm{Fe}_{14} \mathrm{~B}$ and site preference of $\mathrm{V}, \mathrm{Cr}, \mathrm{Mn}, \mathrm{Zr}$ and Nb," Journal of Magnetism and Magnetic Materials, vol. 295, no. 3, pp. 219-229, 2005.

[23] Y. Y. Li, J. Shen, and Y. Chen, "Atomistic simulation for disordered $\mathrm{TbCu}_{7}$-type compounds $\mathrm{SmCo}_{7}$ and $\mathrm{Sm}(\mathrm{Co}, \mathrm{T})_{7}(\mathrm{~T}$ = Ti, Ga, Si, Cu, Hf, Zr)," Solid State Sciences, vol. 12, no. 1, pp. 33-38, 2010.

[24] Y. Long, N. X. Chen, and W. Q. Zhang, "Pair potentials for a metal-ceramic interface by inversion of adhesive energy," Journal of Physics, vol. 17, no. 12, pp. 2045-2058, 2005.

[25] Y. Long and N. X. Chen, "Traces of semigroups associated with interacting particle systems," Journal of Physics, vol. 19, no. 2, pp. 196-216, 2007.

[26] J. Y. Xie, N. X. Chen, J. Shen, L. D. Teng, and S. Seetharaman, "Atomistic study on the structure and thermodynamic properties of $\mathrm{Cr}_{7} \mathrm{C}_{3}, \mathrm{Mn}_{7} \mathrm{C}_{3}, \mathrm{Fe}_{7} \mathrm{C}_{3}$," Acta Materialia, vol. 53, no. 9, pp. 2727-2732, 2005.

[27] J. Y. Xie, N. X. Chen, L. D. Teng, and S. Seetharaman, "Atomistic study on the site preference and thermodynamic properties for $\mathrm{Cr}_{23-x} \mathrm{Fe}_{x} \mathrm{C}_{6}$ "' Acta Materialia, vol. 53, no. 20, pp. 5305-5312, 2005.

[28] J. Y. Xie, J. Shen, N. X. Chen, and S. Seetharaman, "Site preference and mechanical properties of $\mathrm{Cr}_{23-x} \mathrm{~T}_{x} \mathrm{C}_{6}$ and $\mathrm{Fe}_{21} \mathrm{~T}_{2} \mathrm{C}_{6}(\mathrm{~T}$ = Mo, W)," Acta Materialia, vol. 54, no. 18, pp. 4653-4658, 2006.

[29] V. L. Moruzzi, J. F. Janak, and A. R. Williams, Calculated Electronic Properties of Metals, Pergamon, Oxford, UK, 1978. 

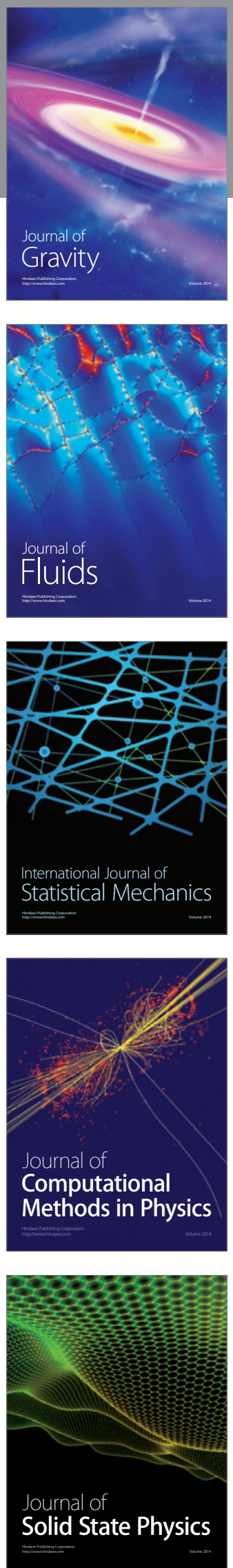

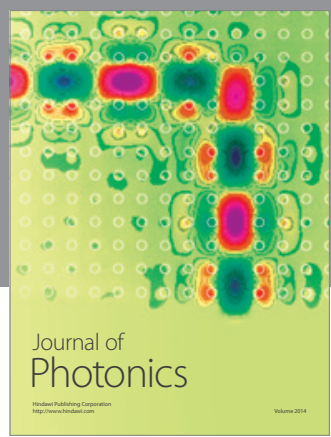

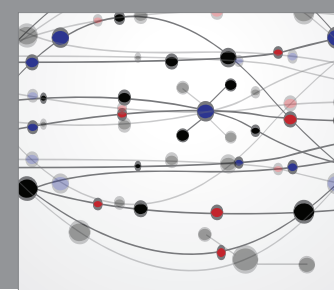

The Scientific World Journal

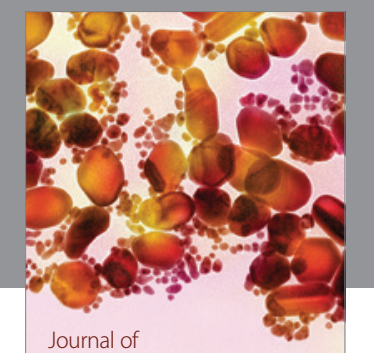

Soft Matter
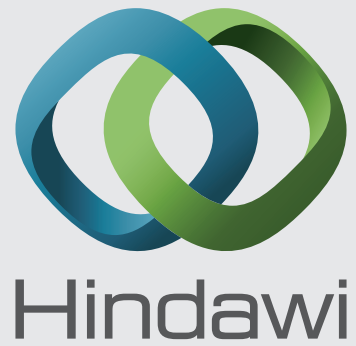

Submit your manuscripts at

http://www.hindawi.com
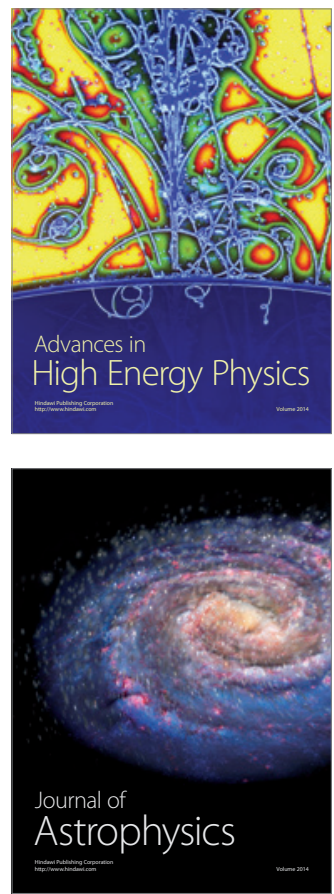
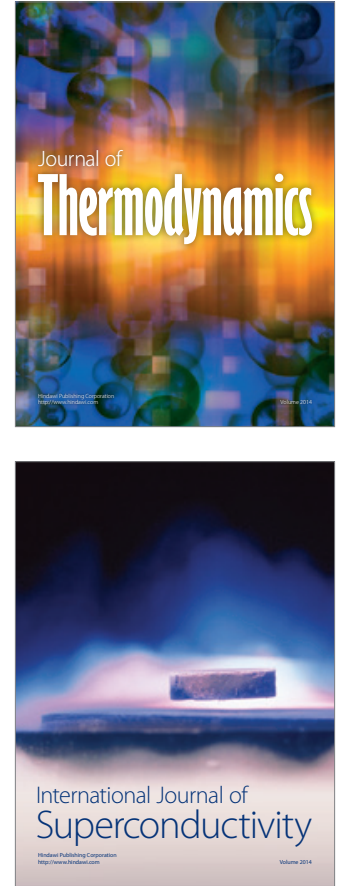
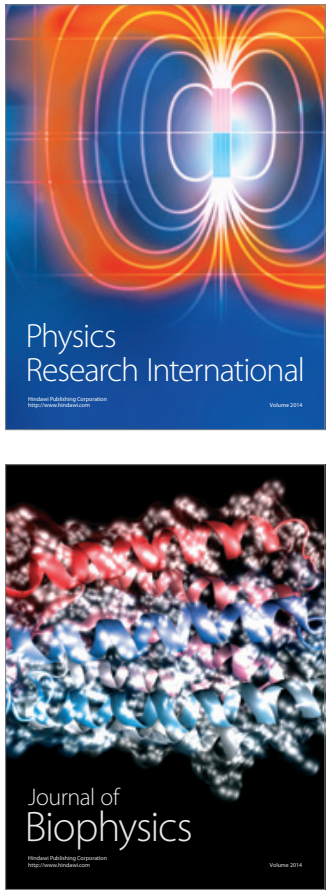
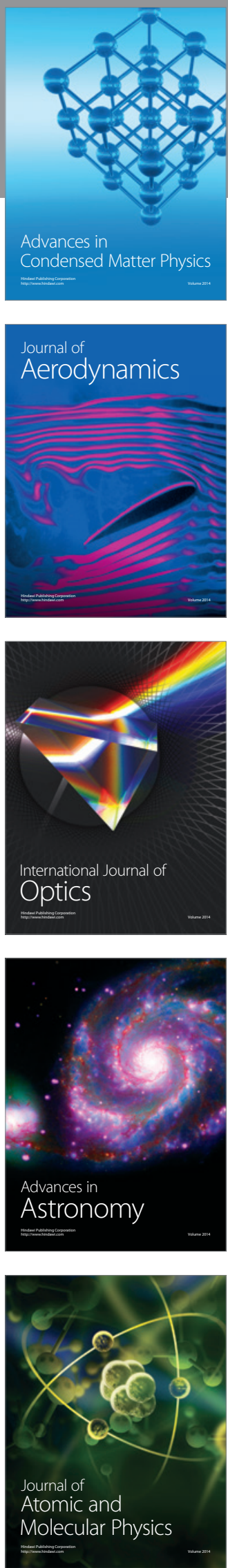